\title{
Spontaneous and CRISPR/Cas9-induced mutation of the osmosensor histidine kinase of the canola pathogen Leptosphaeria maculans
}

\author{
Alexander Idnurm ${ }^{1 *} \mathbb{D}$, Andrew S. Urquhart ${ }^{1}$, Dinesh R. Vummadi ${ }^{1}$, Steven Chang ${ }^{2}$, Angela P. Van de Wouw ${ }^{1}$ \\ and Francisco J. López-Ruiz²
}

\begin{abstract}
Background: The dicarboximide fungicide iprodione has been used to combat blackleg disease of canola (Brassica napus), caused by the fungus Leptosphaeria maculans. For example, in Australia the fungicide was used in the late 1990 s but is no longer registered for use against blackleg disease, and therefore the impact of iprodione on L. maculans has not been investigated.

Results: Resistance to iprodione emerged spontaneously under in vitro conditions at high frequency. A basis for this resistance was mutations in the hos 1 gene that encodes a predicted osmosensing histidine kinase. While loss of the homologous histidine kinase in some fungi has deleterious effects on growth and pathogenicity, the L. maculans strains with the hos 1 gene mutated had reduced growth under high salt conditions, but were still capable of causing lesions on B. napus. The relative ease to isolate mutants with resistance to iprodione provided a method to develop and then optimize a CRISPR/Cas9 system for gene disruptions in L. maculans, a species that until now has been particularly difficult to manipulate by targeted gene disruptions.
\end{abstract}

Conclusions: While iprodione is initially effective against L. maculans in vitro, resistance emerges easily and these strains are able to cause lesions on canola. This may explain the limited efficacy of iprodione in field conditions. Iprodione resistance, such as through mutations of genes like hos1, provides an effective direction for the optimization of gene disruption techniques.

Keywords: Agrobacterium-mediated transformation, Canola, Gene editing, HOG pathway

\section{Background}

Canola (Brassica napus) is a major crop worldwide, and is also grown as part of the crop rotation systems with cereals [1]. Control of the main disease of canola, blackleg, is through farming practices that minimize exposure to the infectious spores, sowing cultivars that carry resistance genes, and more recently relying on fungicides. Blackleg disease is caused by a species complex in the genus Leptosphaeria (Dothideomycetes; Pleosporales) [2-4], with most crop losses due to L. maculans. Although a number of molecular biology resources are available for

\footnotetext{
*Correspondence: alexander.idnurm@unimelb.edu.au

1 School of BioSciences, University of Melbourne, Building 122, Parkville, VIC 3010, Australia

Full list of author information is available at the end of the article
}

L. maculans, including a genome sequence [5], investigations of gene functions in the fungus has been hampered by the low rates of homologous integration of constructs used in generating gene deletion strains, with just nine gene knock outs reported in the literature [6-11]. Hence, this aspect of the fungus has limited the ability to test how specific genes may impact the ability of this fungus to cause disease on canola.

The application of fungicides has provided large yield increases to crops by reducing the symptoms caused by fungal diseases. In the case of blackleg disease, different fungicides have been and continue to be employed [1]. In Australia, currently these are in the triazole class [Fungicide Resistance Action Committee (FRAC) group 3], and used as seed dressings, combined with fertilizer, or as a foliar 
spray. In another class, the dicarboximide iprodione (FRAC group 2; trade name Rovral ${ }^{\circledR}$ produced by Bayer CropScience), was approved for use against blackleg disease and used for about 5 years before being unregistered at the end of the 1990s. Iprodione currently can still be used for treatment of Sclerotinia stem rot of canola, which is a disease that has an overlapping distribution as blackleg.

Resistance to dicarboximide fungicides, like iprodione, can occur if mutations arise in the high osmolarity glycerol response (HOG) pathway [12]. The HOG pathway was first characterized in Saccharomyces cerevisiae for its role in enabling growth under hyper- and hypo-osmotic conditions [13-15], and subsequent research in numerous fungal species has defined multiple phenotypes of strains with mutations in the signaling genes. The HOG pathway features a sensing histidine kinase that transfers environmental information into a cascade of three mitogen activated protein kinases [12]. Mutations often occur in the homologs of the histidine kinase in other fungi to confer resistance to the dicarboximide fungicides [16].

Exposure to fungicides is linked to the emergence of fungicide resistance, thereby rendering specific fungicides or entire classes ineffective. We recently initiated an investigation into the levels of resistance to triazole fungicides in L. maculans populations in Australia [17]. As a control, isolates were tested for their responses against the unrelated chemical iprodione. Spontaneous resistance to this molecule was commonly observed, leading to the investigation into its basis and the impact of those mutations on pathogenicity. Subsequently, the hos1 gene that was mutated in these resistant strains was used as a tool for the development of the clustered regularly interspaced short palindromic repeats (CRISPR)-Cas9 system to make targeted mutations in $L$. maculans.

\section{Methods}

\section{Fungal strains and culturing}

Routine culturing of $L$. maculans was on $10 \%$ V8 juice with $2 \%$ agar. The wild type strains or those isolated during this study are listed in Table 1 . Because there is often limited contrast between the color of the V8 juice and fungal hyphae, to increase the contrast in the figures the strains were cultured on potato dextrose agar. Iprodione was dissolved in dimethyl sulfoxide, and added to agar media at final concentrations of 5 or $10 \mu \mathrm{g} / \mathrm{ml}$.

Table 1 Strains of Leptosphaeria spp. used in this study

\begin{tabular}{|c|c|c|}
\hline Strain name(s) & Genotype & Origin \\
\hline L. biglobosa 06J154 & Wild type & Burren Junction, NSW, Australia, 2006 [19] \\
\hline D5 (IBCN18; M1) & Wild type & Penshurst, VIC, Australia, 1988 \\
\hline D5-I $p^{R}$ & $\operatorname{hos} 1^{-}$ & Selection of D5 on iprodione \\
\hline$D 5-1 p^{R}+$ hos 1 & $\operatorname{hos} 1^{-}+\operatorname{hos} 1$ & Transformation of D5-Ip ${ }^{R}$ with wild type hos 1 \\
\hline D2 (IBCN15) & Wild type & Streatham, VIC, Australia, 1988 [2] \\
\hline D2-Ip $p^{R}$ & $\operatorname{hos} 1^{-}$ & Selection of D2 on iprodione \\
\hline$D 2-I p^{R}+$ hos 1 & $\operatorname{hos} 1^{-}+$hos1 & Transformation of D2-Ip ${ }^{R}$ with wild type hos 1 \\
\hline D3 (IBCN16) & Wild type & Mt Barker, WA, Australia, 1988 [2] \\
\hline D3-I $p^{R}$ & $\operatorname{hos} 1^{-}$ & Selection of D3 on iprodione \\
\hline D3-Ip + hos 1 & $\operatorname{hos} 1^{-}+\operatorname{hos} 1$ & Transformation of D3-I $p^{R}$ with wild type hos 1 \\
\hline 14P290 & Wild type & Katanning, WA, Australia, 2014 [17] \\
\hline $14 \mathrm{P} 290-\mathrm{I} \mathrm{p}^{\mathrm{R}}$ & $\operatorname{hos} 1^{-}$ & Selection of 14P290 on iprodione \\
\hline $14 \mathrm{P} 290-\mid p^{R}+$ hos 1 & $\operatorname{hos} 1^{-}+\operatorname{hos} 1$ & Transformation of 14P290-Ip ${ }^{R}$ with wild type hos 1 \\
\hline D13 (09SMW024) & Wild type & Cummins, SA, Australia, 2009 [52] \\
\hline DV1 & hos1 guide & D5 \\
\hline DV2 & hos 1 guide; cas 9 & DV1 \\
\hline DV3 & hos 1 guide; $\operatorname{cas} 9 ;$ hos $1^{-}$ & DV2 \\
\hline D13-CoT & cas9; hos1 guide & D13 cotranformed with both guide RNA (hyg) and Cas9 (G418) \\
\hline D13-Ip ${ }^{R} 1$ & cas9; hos1 guide; hos 1- & Selection of D13-CoT on iprodione \\
\hline$D 13-I p^{R} 2$ & cas9; hos 1 guide; hos $1^{-}$ & Selection of D13-CoT on iprodione \\
\hline v23.1.3 & Wild type & In vitro crosses, France [5] \\
\hline JN3-Cas9 & $\operatorname{cas} 9$ & v23.1.3 transformed with pMAI23 \\
\hline JN3-avrLm1-1 & cas9; AvrLm1 guide; avrLm1- & JN3-Cas9 \\
\hline JN3-avrLm1-2 & cas9; AvrLm1 guide; avrLm1- & JN3-Cas9 \\
\hline
\end{tabular}

All strains are L. maculans, with the exception of one L. biglobosa strain used as a source of DNA for constructs. The numerous hos 1 mutants isolated from CRISPR-Cas9 sources and the 28 progeny from the D3-I $p^{R} \times$ D13 cross are not listed. IBCN indicates a strain in the International Blackleg of Crucifers Network collection 
For genetic segregation analysis, crosses were set up between strain D3-Ip ${ }^{\mathrm{R}}$ and strain D13, on $20 \%$ V8 juice and $\mathrm{CaCO}_{3}$ medium. After 1 week of growth, the plates were overlaid with water agar. Cultures were incubated at $14{ }^{\circ} \mathrm{C}$ with alternating $12 \mathrm{~h}$ dark-blacklight cycles for 6 weeks. At this point, the plates were examined for the formation of pseudothecia. Asci were released by placing the pseudothecia in sterile water whereby ascospores were discharged naturally. Individual ascospores were then collected and allowed to germinate on $2 \%$ water agar plates before being hyphal-tip subcultured to create individual strains. A total of 28 progeny was collected and analyzed.

\section{DNA isolation of $L$. maculans, PCR and sequencing}

Leptosphaeria maculans mycelia were cultured in $10 \%$ cleared V8 juice medium ( $\mathrm{pH} \mathrm{6).} \mathrm{Mycelia} \mathrm{were} \mathrm{freeze-}$ dried, broken with $2 \mathrm{~mm}$ glass beads, and DNA extracted in a CTAB buffer and incubation at $65{ }^{\circ} \mathrm{C}$, followed by one chloroform extraction, and precipitation with an equal volume of isopropanol [18].

For sequencing, hos1 was amplified with different primer combinations to cover different regions of this large gene. Amplicons used to identify spontaneous mutations were MAI0218-MAI0223 and MAI0220MAI0224. Primer sequences used in this study are found in Additional file 1: Table S1. Primers used to amplify and then identify mutations in hos 1 induced by CRISPR-Cas9 were MAI0220-MAI0224.

To resolve which hos 1 allele is present in progeny of the D3-Ip ${ }^{R} \times$ D13 cross, the region was amplified with primers MAI0220-MAI0376. The DNA was precipitated and then digested with AgeI restriction enzyme, which cuts the amplicon of the wild type copy but not the iprodione resistance allele.

Primers used to amplify the AvrLm1 gene to identify mutations induced by CRISPR-Cas9 were MAI0353-MAI0354.

\section{Construction of plasmids for transformation of L. maculans}

Plasmids were constructed for the introduction of T-DNA molecules into L. maculans using Agrobacterium tumefaciens mediated transformation.

Two plasmids conferring resistance to G418 or hygromycin were made, in which gene expression was from the promoter and terminator of the actin gene of $L$. biglobosa strain 06J154 [19]. G418 resistance has not been used previously in L. maculans transformation. For the G418 construct, the promoter region was amplified with primers MAI0014-MAI0015, and terminator region with primers MAI0016-MAI0017 from genomic DNA of strain 06J154, isolated as for L. maculans. The open reading for the aminoglycoside phosphotransferase that confers resistance to G418 was amplified with primers ALID0835-ALID0836 from plasmid pPZP-NEO1 [20]. The three pieces were joined by overlap PCR using primers MAI0014-MAI0017, and cloned into the TOPO pCR2.1 plasmid (Invitrogen). To ensure the expression system worked for resistance to G418, the equivalent plasmid was made to confer resistance to hygromycin. The promoter was amplified with primers MAI0018MAI0024 and terminator with MAI0020-MAI0021. The hygromycin phosphotransferase gene was amplified with primers MAI0022-MAI0023 from plasmid pPZPHygHindX [21]. The three pieces were joined together using primers MAI0018-MAI0021, and cloned into the TOPO 4.0 plasmid (Invitrogen). All PCRs used Platinum ${ }^{\circledR} P f x$ DNA polymerase (Invitrogen). Plasmids containing clones without PCR-derived errors were identified, by sequencing the inserted fragments. The G418 resistance construct was excised with EcoRI and cloned into the EcoRI site of plasmid pPZP-201BK, which is able to replicate in Agrobacterium tumefaciens [22], to form pMAI2. The hygromycin resistance construct was excised with KpnI-SpeI and cloned into the KpnI-XbaI site of pPZP-201BK to form plasmid pMAI6.

Plasmid pLAU2 was constructed by cloning two fragments, the L. maculans actin (act1) promoter and the trp3 terminator, into pPZPHygHindX [21] digested with AscI and PacI using Gibson Assembly (New England Biolabs). Primers used to amplify the actin promoter, with Platinum ${ }^{\circledR}$ Pf $x$ DNA Polymerase (Invitrogen), were AU1 and AU2 and for the trp3 terminator were AU5 and AU6. Primers were designed with additional nucleotides such that a BglII site was introduced between the promoter and terminator. Green fluorescent protein (GFP) was amplified with primers AU28 and AU31, and cloned into the BglII site of pLAU2 to form plasmid pLAU17. The act 1 promoter and trp 3 terminator combination was excised from plasmid pLAU2 using restriction enzymes SpeI and NheI and cloned into the $\mathrm{XbaI}$ site of plasmid pMAI2, to form pLAU53.

For complementation with the wild type copy of hos 1, the gene was amplified with primers MAI0206 and MAI0207 using Q5 DNA polymerase (New England Biolabs) from genomic DNA of wild type isolate D5, and cloned using Gibson assembly (New England Biolabs) into plasmid pMAI2 that had been linearized with EcoRV and XhoI.

Constructs were made to express either the Cas9 endonuclease or the CRISPR guide RNAs using the actin promoter of L. maculans. Cas9 was amplified with primers MAI0225 and MAI0226 from plasmid pHSN401 [23] and cloned into the BglII sites of pLAU2 and pLAU53 by Gibson assembly to form plasmids pMAI22 and pMAI23, respectively. The DNA fragment to target the 
endonuclease to hos1, guide RNA and two ribozymes were synthesized by Thermo Fisher Scientific (sequence in Additional file 2) and provided as a cloned product. The fragment was amplified using primers MAI0228 and MAI0229 and then inserted into the BglII sites of both plasmids pLAU2 and pLAU53 using Gibson assembly.

To streamline the production of the guide RNAs, two additional plasmids were made that incorporate the hepatitis delta virus (HDV) ribozyme, such that a single oligonucleotide of about $100 \mathrm{nt}$ can be used for cloning the targeting RNA, rather than a synthesized and cloned DNA fragment. A XhoI restriction enzyme site was included to facilitate subsequent cloning of the gene-specific fragments. A DNA molecule (Additional file 2) was synthesized by Thermo Fisher Scientific, and amplified with primers MAI0228-MAI0229 and cloned into the BglII sites of both plasmids pLAU2 and pLAU53 using Gibson assembly to form plasmids pMAI75 and pMAI97, respectively.

A construct to produce a guide RNA to target mutations to the AvrLm1 gene was generated, by amplification off oligonucleotide MAI0336 with primers MAI0309MAI0310, and cloning the amplicon into plasmid pMAI75 linearized with XhoI.

In all cases of plasmid construction that used amplification of DNA and subsequent cloning, the inserted DNA molecules in the plasmids were sequenced to either confirm that no PCR-induced errors occurred or to identify error-free clones.

\section{Transformation of L. maculans with Agrobacterium tumefaciens}

The plasmids were transformed into A. tumefaciens strain EHA105 using electroporation, and selected on LB medium + kanamycin $(50 \mu \mathrm{g} / \mathrm{ml})$. The Agrobacterium strains were then used to transform strains of $L$. maculans, with selection of fungal transformants using either G418 $(100 \mu \mathrm{g} / \mathrm{ml})$ or hygromycin $(50 \mu \mathrm{g} / \mathrm{ml})$, and cefotaxime $(100-150 \mu \mathrm{g} / \mathrm{ml})$ to inhibit Agrobacterium growth. The transformation of $L$. maculans was as follows. Overnight cultures of Agrobacterium in LB + kanamycin were diluted in sterile water and plated onto Agrobacterium induction medium [24] solidified with $2 \%$ agar $(25 \mathrm{ml}$ in $15 \mathrm{~cm}$ diameter Petri dishes) with pycnidiospores harvested in sterilized water from the $L$. maculans strains. Bacterial and fungal cells were spread across the plate. After 3 days incubation at $22{ }^{\circ} \mathrm{C}$ in darkness, $25 \mathrm{ml}$ of cleared V8 juice $1.5 \%$ agar media containing selective antibiotics were overlaid. Transformed colonies emerged through the overlay agar 10-18 days later. The transformed strains were subcultured at least once onto V8 juice agar supplemented with the antibiotic suitable to select for fungal transformation and cefotaxime to inhibit Agrobacterium growth.

\section{Quantification of antifungal drug resistance}

Levels of resistance to two dicarboximide fungicides and a triazole fungicide were quantified in a radial growth assay, as in Ref. [25] with some modifications. In brief, for each strain $4 \mathrm{~mm}$ diameter mycelium plugs were inoculated into the center of 9-cm PDA petri dishes amended with a range of concentrations of technical grade iprodione $(0.195-50 \mu \mathrm{g} / \mathrm{ml})$, procymidone $(0.195-50 \mu \mathrm{g} / \mathrm{ml})$ and tebuconazole $(0.0782-5 \mu \mathrm{g} / \mathrm{ml})$ dissolved in dimethyl sulfoxide (DMSO). The colony diameter was measured in two perpendicular directions and values recorded in millimeters. $\mathrm{EC}_{50}$ values were calculated as described previously [16]. $\mathrm{EC}_{50}$ values of wild type and complemented strains were analyzed by the Mann-Whitney $U$-test.

\section{Microscopy}

Spores of wild type and a GFP-expressing strain were germinated in cleared V8 juice (10\%) and examined 3 days later using a Leica DM6000 microscope with an attached digital camera.

\section{Plant inoculations and pathogenicity testing}

Brassica napus cultivar Westar was grown in soil in growth cabinets. Two weeks after sowing the seed, pycnidiospore suspensions $\left(10^{6}\right.$ spores $\left./ \mathrm{ml}\right)$ from the L. maculans strains were placed as $10 \mu \mathrm{l}$ drops onto wounded cotyledons. Lesions were scored on a 0-9 scale, as previously described [26], 11-14 days later.

\section{Results}

Development of a positive selection system in L. maculans based on resistance to iprodione due to mutations in the hos1 gene

Wild type strains of L. maculans developed resistance to iprodione readily when mycelial plugs were inoculated on V8 juice agar medium supplemented with iprodione at concentrations up to $10 \mu \mathrm{g} / \mathrm{ml}$. The fungicide at first inhibited growth, and then after several days a section of the mycelial plug initiated growth. These sectors were cultured and purified as single spore isolates.

A single homolog, named hos 1, of the osmosensing histidine kinase is present in L. maculans as assessed by BLAST analysis of the genome sequence [5]. Amplification of the hos1 gene and sequencing revealed mutations in the gene in iprodione resistant mutants, all of which are predicted to cause a loss-of-function (Fig. 1a). Two mutants, one arising from strain D2 (referred to as D2-Ip ${ }^{\mathrm{R}}$ ) and the other from strain 14P290 (P290-Ip $\left.{ }^{\mathrm{R}}\right)$, cause frame shifts in the reading frame, leading to the introduction of premature stop codons. The mutations that occurred in the mutants arising from strains D5 (D5-Ip $\left.{ }^{\mathrm{R}}\right)$ and D3 (D3-Ip $\left.{ }^{\mathrm{R}}\right)$ cause amino acid substitutions (R923K and G929R, respectively). These two amino acid residues are highly 


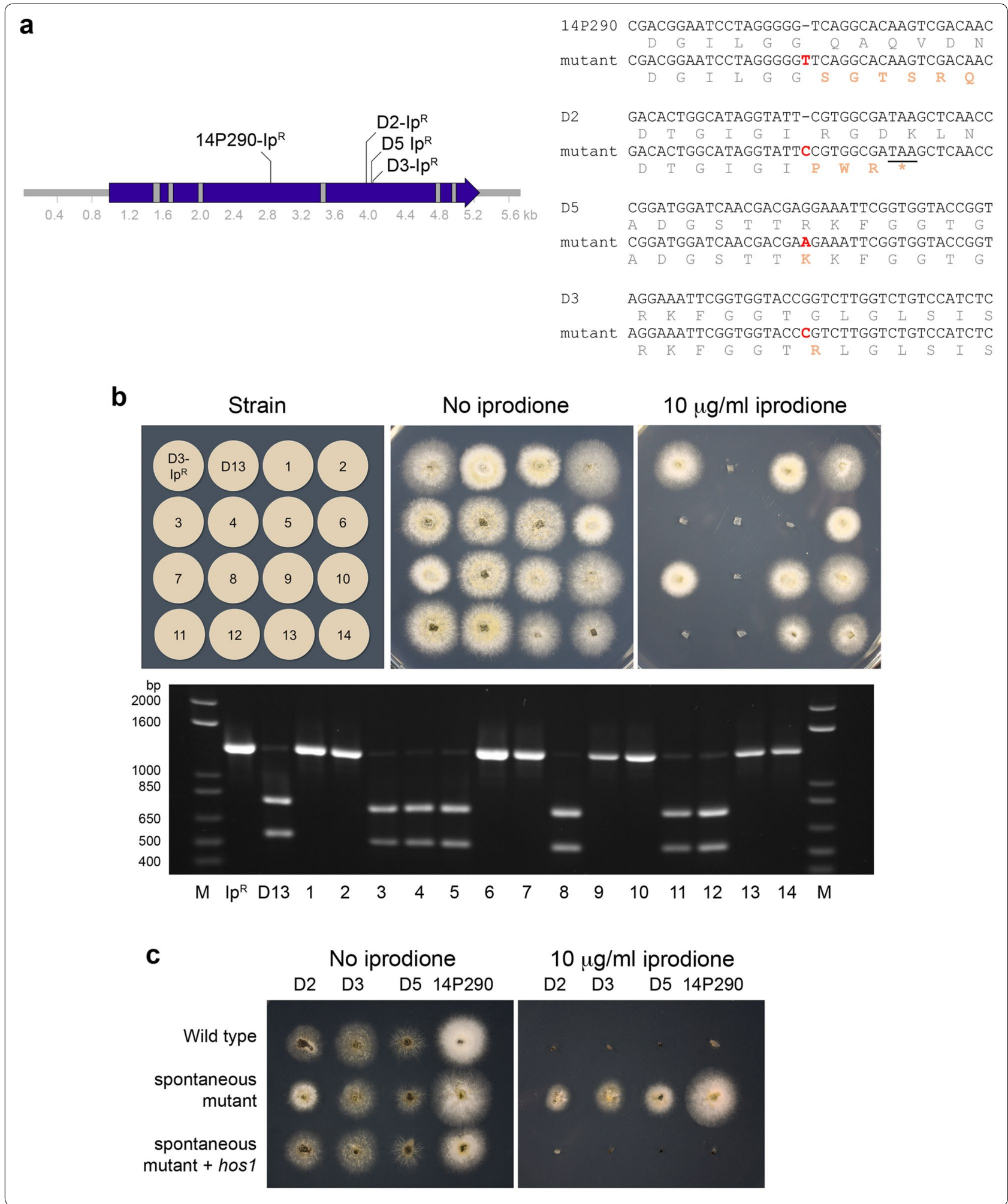


(See figure on previous page.)

Fig. 1 Spontaneous iprodione resistance occurs through mutation of the hos 1 gene. a Positions and nature of spontaneous mutations in iprodione resistant strains from four wild type strains relative to the exon (blue) and intron (grey) structure of the hos 1 gene. The sequence alignments are of the wild type and mutant strains, with the nucleotide mutations that occurred in the four strains in red bold, and the predicted amino acid sequences underneath. The mutations in strains 14P290 and D2 cause frame shifts (the stop codon in the D2 mutant is underlined, in 14P290 the new stop codon is beyond the sequence shown). The mutations in M1 and D3 cause amino acid substitutions in residues that are invariant across hos 1 homologs in the fungi. b A mutation in hos 1 co-segregates with iprodione resistance. Growth of two parents and 14 progeny (from 28 total) of a D13 $\times$ D3-I $p^{R}$ cross between the parents on PDA with or without iprodione. The alleles of hos 1 were assessed by PCR from genomic DNA of the two parents and 14 progeny from a cross between them, and subsequent digestion with Agel restriction enzyme. M is the Invitrogen $1 \mathrm{~kb}+$ ladder. c Complementation of iprodione resistance back to sensitivity by the wild type hos 1 gene. Mycelial plugs were inoculated onto PDA medium with or without iprodione $(10 \mu \mathrm{g} / \mathrm{ml})$ and cultured 4 days. The strains are four wild type strains, four spontaneous mutants derived from them, and the four strains whereby the wild type copy of hos 1 was transformed into the mutants. The wild type copy of hos 1 returned the strains to the wild type sensitive phenotype

conserved in homologs of the histidine kinase, because BLAST analysis of the fungal genomes available through the MycoCosm Portal of the Joint Genome Institute [27] revealed that both residues are invariant in all fungal species, including those of the early diverging lineages commonly termed the chytrids and zygomycetes.

Two methods were used to confirm that mutations in the hos 1 gene caused the resistance to iprodione. The first approach was to analyze the segregation of traits and genotypes in progeny from a cross. Resistant strain D3-Ip ${ }^{R}$ was crossed with sensitive strain D13, and 28 progeny obtained. The strains were scored for growth on medium containing iprodione and genotyped for the hos 1 allele by PCR-RFLP. The AgeI restriction enzyme recognition site (ACCGGT) of the wild type strain is lost in strain D3-Ip ${ }^{\mathrm{R}}$ due to a base pair substitution (ACCEGT), as underlined. Nine progeny were sensitive to iprodione and 19 were resistant, which is not statistically different from the expected 1:1 ratio based on a $\chi^{2}$-test. The AgeI cut site polymorphism in hos1 co-segregated with the iprodione sensitive or resistant phenotype (Fig. 1b). The second approach was complementation of the mutant phenotype. A wild type copy of the hos 1 gene was amplified and cloned into a plasmid that confers resistance to G418 for selection when the T-DNA is transformed into L. maculans. This construct was transformed into four strains that were iprodione resistant (i.e. D2-Ip ${ }^{\mathrm{R}}$, D3-Ip ${ }^{\mathrm{R}}$, D5-Ip ${ }^{\mathrm{R}}$ and 14P290-Ip ${ }^{\mathrm{R}}$ ). Transformants were tested on medium containing iprodione. Reintroducing the wild type copy of hos1 into the strains caused them to become sensitive once again to iprodione, indicating that the mutations identified in hos1 were the cause of the resistance to this antifungal agent (Fig. 1c).

A quantitative assay was used to measure the level of resistance to iprodione, a second dicarboximide chemical, procymidone, and an azole, tebuconazole, in four sets of strains (Table 2). The minimum inhibitory concentration was between 1 and $2 \mu \mathrm{g} / \mathrm{ml}$ for the wild type strains

Table 2 Half maximal effective concentration $\left(E C_{50}\right)$ measurements of fungicide action for strains of $L$. maculans

\begin{tabular}{|c|c|c|c|c|c|c|}
\hline \multirow[t]{2}{*}{ Strain } & \multicolumn{2}{|c|}{ Iprodione $\mathrm{EC}_{50}(\mu \mathrm{g} / \mathrm{ml})$} & \multicolumn{2}{|c|}{ Procymidone $\mathrm{EC}_{50}(\mu \mathrm{g} / \mathrm{ml})$} & \multicolumn{2}{|c|}{ Tebuconazole $\mathrm{EC}_{50}(\mu \mathrm{g} / \mathrm{ml})$} \\
\hline & Average & SD & Average & SD & Average & SD \\
\hline P290 & 1.25 & 0.09 & 1.75 & 0.04 & 0.29 & 0.01 \\
\hline P290-I $p^{R}$ & $>50$ & & $>50$ & & 0.53 & 0.01 \\
\hline P290-I $p^{R}+$ hos 1 & 1.32 & 0.09 & 1.70 & 0.01 & 1.12 & 0.34 \\
\hline D2 & 1.10 & 0.22 & 1.94 & 0.12 & 0.40 & 0.14 \\
\hline$D 2-1 p^{R}$ & $>50$ & & $>50$ & & 0.39 & 0.02 \\
\hline $\mathrm{D} 2-1 p^{R}+$ hos 1 & 0.94 & 0.11 & 2.66 & 0.16 & 0.43 & 0.00 \\
\hline D3 & 1.21 & 0.06 & 1.84 & 0.13 & 0.91 & 0.01 \\
\hline D3-I $p^{R}$ & $>50$ & & $>50$ & & 0.51 & 0.02 \\
\hline D3-Ip + hos 1 & 1.07 & 0.10 & 1.73 & 0.06 & 0.77 & 0.01 \\
\hline D5 & 0.43 & 0.27 & 1.57 & 0.20 & 0.50 & 0.03 \\
\hline D5-I $p^{R}$ & $>50$ & & $>50$ & & 0.10 & 0.05 \\
\hline D5-Ip + hos 1 & 0.48 & 0.28 & 1.25 & 0.23 & 0.14 & 0.00 \\
\hline
\end{tabular}

$S D$ standard deviation 
for the dicarboximides. The strains derived from selection on iprodione were not inhibited with these chemicals at concentrations up to $50 \mu \mathrm{g} / \mathrm{ml}$. Complementation of the strains with the wild type copy of hos1 restored the $\mathrm{EC}_{50}$ values to close to those seen in the wild type parents. In contrast, resistance to the unrelated molecule, tebuconazole (FRAC group 3), was not altered. Analysis of the results revealed no significant differences between wild type and restored strains on iprodione $(p=0.200$ $1.00)$, procymidone $(p=0.057-0.686)$ and tebuconazole $(p=0.333-1.00)$.

Mutation of the HOG pathway components is also responsible for other phenotypes in fungi, the best known being changes in growth in the presence of the phenylpyrrole fungicide fludioxonil (FRAC group 12) and salt [12]. Using growth on plates, a wild type D5, hos ${ }^{-}$ mutant (D5-Ip ${ }^{\mathrm{R}}$ ) and a + hos1 complemented strain (D5-Ip ${ }^{\mathrm{R}}+$ hos1) were examined for these properties. As has been reported for other fungi, mutation of hos1 resulted in increased resistance to fludioxonil and an increased sensitivity to sodium chloride (Fig. 2).

Growth in planta can be considered an environment of high stress to plant pathogenic fungi. Three $L$. maculans strains were inoculated onto wounded $B$. napus cotyledons, and lesion formation was examined over time. No difference in pathogenicity was observed between the three strains (average disease scores for wild type 6.14, hos $1^{-}$mutant 6.03 and + hos1 complementated 6.73;

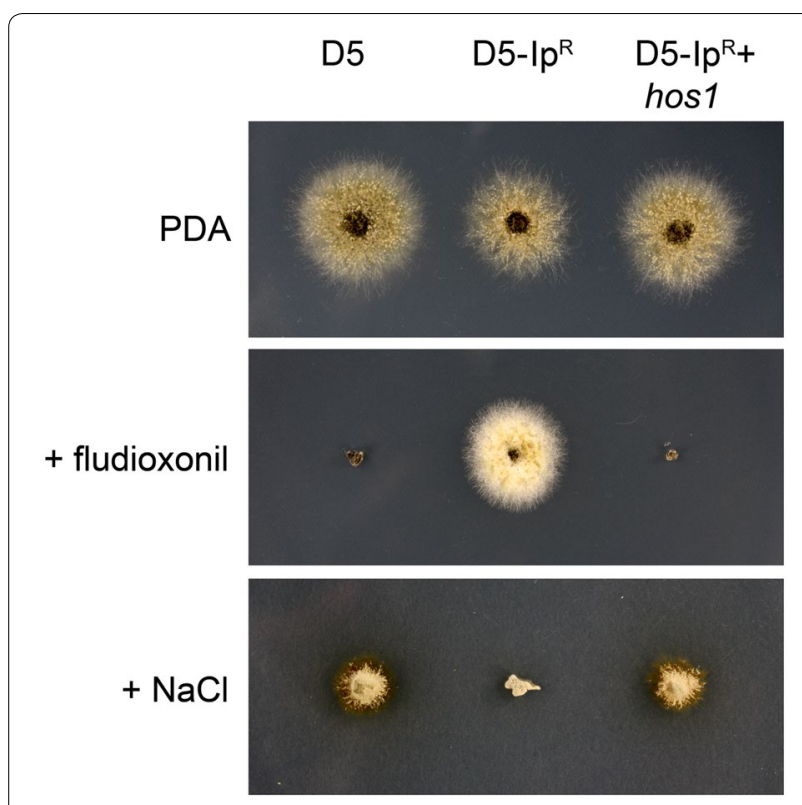

Fig. 2 Mutation of hos 1 causes L. maculans to become resistant to the fungicide fludioxonil and more sensitive to $\mathrm{NaCl}$. Strains D5, D5-I $\mathrm{p}^{\mathrm{R}}$ and D5-I $\mathrm{p}^{\mathrm{R}}+$ hos 1 and were cultured of PDA, and with PDA supplemented with fludioxonil $(1 \mu \mathrm{g} / \mathrm{ml})$ or $\mathrm{NaCl}(0.5 \mathrm{M})$
Fig. 3), indicating that hos1 is not required for the ability of $L$. maculans to cause disease on canola.

\section{Development of a CRISPR/Cas9 gene disruption system for L. maculans}

Identification of gene functions in L. maculans through targeted gene replacements has been inefficient due to low rates of homologous integration of constructs. The potential to use a positive selection system, i.e. growth on iprodione when hos1 is mutated, was an impetus to use the hos1 gene for the development of gene targeting methods, specifically through CRISPR-Cas9.

A versatile pair of plasmids (pLAU2 and pLAU53) was created for strong constitutive transcription of DNA sequences that are cloned into them. Both plasmids feature the $1001 \mathrm{bp}$ prior to the start codon (the promoter) of the act1 gene, encoding an actin subunit, and the terminator of $\operatorname{trp} 3$ encoding anthranilate synthase of $L$. maculans. Actin is considered to be constitutively expressed and is commonly used as the reference gene in quantitative reverse transcriptase PCR experiments [21, $28,29]$. The plasmid includes a BglII site between the promoter and terminator into which genes or other DNA fragments can be cloned. To test if this promoter and terminator combination was able to drive protein production, the open reading frame for GFP was cloned into plasmid pLAU2, and the T-DNA transformed into wild type $L$. maculans. Fluorescence was abundant in spores and hyphae of transformants, indicating that the construct induces gene expression and yields high and stable protein synthesis (Additional file 3: Fig. S1).

The open reading frame of the Cas9 endonuclease was amplified and cloned into both the pLAU2 or pLAU53 constructs. Similarly, a hos1 RNA guide construct was cloned into both pLAU2 and pLAU53. As a consequence, different options were available for the order of transformation and selection of transformants. The T-DNAs were sequentially introduced into wild type strain D5, either as the hos1 RNA guide first and Cas9 second (e.g. strains DV1 and DV2), or in the other order, and the transformants were plated onto media containing iprodione $(5 \mu \mathrm{g} / \mathrm{ml})$ to isolate resistant strains (Fig. $4 \mathrm{a})$.

Iprodione resistant strains were cultured as mycelia, genomic DNA isolated, and the region spanning the site for CRISPR-Cas9 induced mutation in the hos1 gene amplified. Amplicons were digested with KpnI restriction enzyme and/or sequenced. All isolates derived from strains expressing both Cas9 and the hos1 RNA guide had mutations in this region (Fig. 4b). Most mutations were either the insertion of an additional nucleotide, or the deletion of one or several nucleotides (Fig. 4b). One strain, which is not illustrated in Fig. $4 \mathrm{~b}$ due to the size of the DNA sequence, had a tandem duplication of $69 \mathrm{bp}$ 


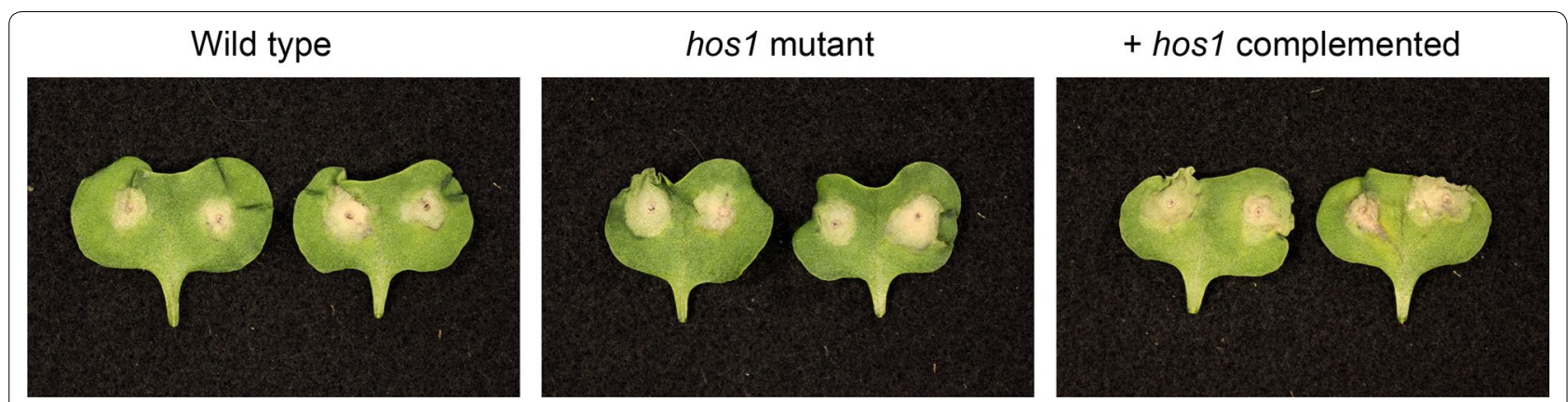

Fig. 3 L. maculans hos 1 mutants are pathogenic on canola. Lesions on B. napus Cv. Westar 11 days post inoculation caused by wild type isolate 14P290, a spontaneous mutation in hos 1 isolated on iprodione medium, and that strain complemented with a wild type copy of hos 1

\section{a}

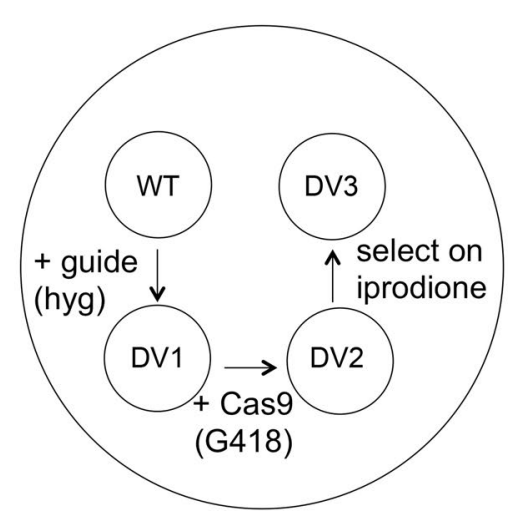

No iprodione

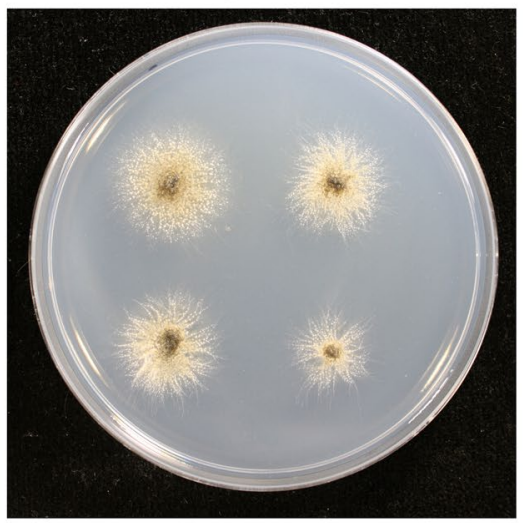

+ iprodione

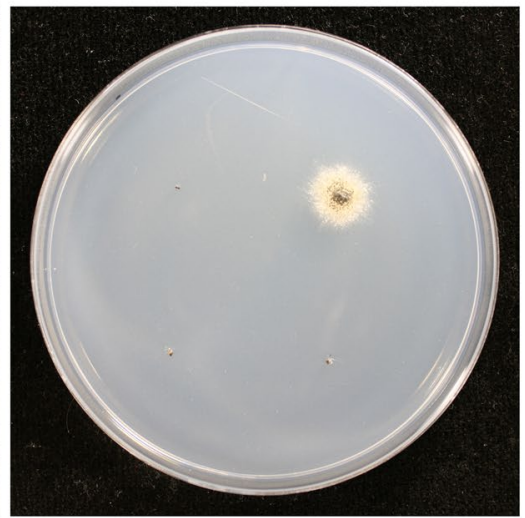

b

Wild type ACTTGGCGGACAGGCTACAGTACATGGTGTCGAGGGT-ACCTGGAAAGACCTCACGGAAAACGTGAATGGTATGGCCATGAATCTCACAACCCAGGTGCGAGAAATCGCAGAAGTC AI0676 ACTTGGCGGACAGGCTACAGTACATGGTGTCGAGGGTTACCTGGAAAGACCTCACGGAAAACGTGAATGGTATGGCCATGAATCTCACAACCCAGGTGCGAGAAATCGCAGAAGTC TC1 ACTTGGCGGACAGGCTACAGTACATGGTGTCGAGGGTTACCTGGAAAGACCTCACGGAAAACGTGAATGGTATGGCCATGAATCTCACAACCCAGGTGCGAAAAATCGCAGAAGTC AI0671 ACTTGGCGGACAGGCTACGGTAC--------------CTGGAAAGACCTCACGGAAAACGTGAATGGTATGGCCATGAATCTCACAACCCAGGTGCGAGAAATCGCAGAAGTC AI0668 ACTTGGCGGACAGGCTACAGTACAT------- GGTATGGCCATGAATCTCACAACCCAGGTGCGAGAAATCGCAGAAGTC AI0675 ACTTGG---_---_--- TATGGCCATGAATCTCACAACCCAGGTGCGAGAAATCGCAGAAGTC AI0669 ACTTGGCGGACAGGCTACAGTACAT---------------AAGACCTCACGGAAAACGTGAATGGTATGGCCATGAATCTCACAACCCAGGTGCGAGAAATCGCAGAAGTC AI0677 ACTTGGCGGACAGGCTACAGTACATGGTGTC------------GACCTCACGGAAAACGTGAATGGTATGGCCATGAATCTCACAACCCAGGTGCGAGAAATCGCAGAAGTC

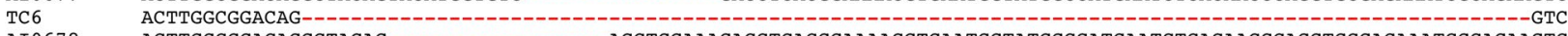
AI0678 ACTTGGCGGACAGGCTACAG-TC2 ACTTGGCGGACAGGCTACAGT-_-_-_-_-_-_-_ACCTGGAAAGACCTCACGGAAAACGTGAATGGTATGGCCATGAATCTCACAACCCACGTGCGAGAAATCGCAAAGGTC

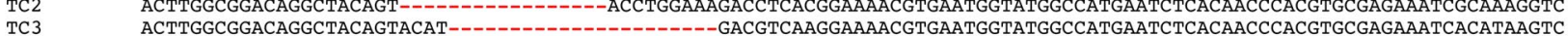

Fig. 4 Development of the CRISPR/Cas9 system for targeted gene disruption in L. maculans. a Phenotype of transformants on plates with or without iprodione. Three strains derive from sequential modification of the wild type (WT) strain D5, first by transformation of the hos 1 guide RNA construct (strain DV1), then transformation of the Cas9 construct (strain DV2), and lastly by selection on iprodione (strain DV3). b Alignment of sequences of hos 1 from the wild type and 11 independently-created iprodione resistant mutants. On the wild type sequence the protospacer adjacent motif (PAM) is in blue highlight, region incorporated in the guide RNA in green highlight, and the Kpnl restriction enzyme site used for screening is underlined. Changes in the sequence in the mutants are in red text

(ACCTGgAa AGACCTCACGga aA ACGTGAATgGTATgGCCATGAATCTCACAACCCAGgTGCGAGAAATC). In all cases the mutations in hos 1 were near the region of the genome where the guide RNA would target Cas9, indicating that they were derived from inaccurate repair of DNA damage by the endonuclease. The types of mutations also often differed from those found in the spontaneous mutants as many featured large deletions, compared to single nucleotide substitutions or insertions.

The pathogenicity of strains from one set of gene manipulations were tested by inoculating B. napus cotyledons. The three strains derived from the wild type produced lesions like the wild type isolate (Additional file 4: Fig. S2). This indicates that the introduction of Cas9 


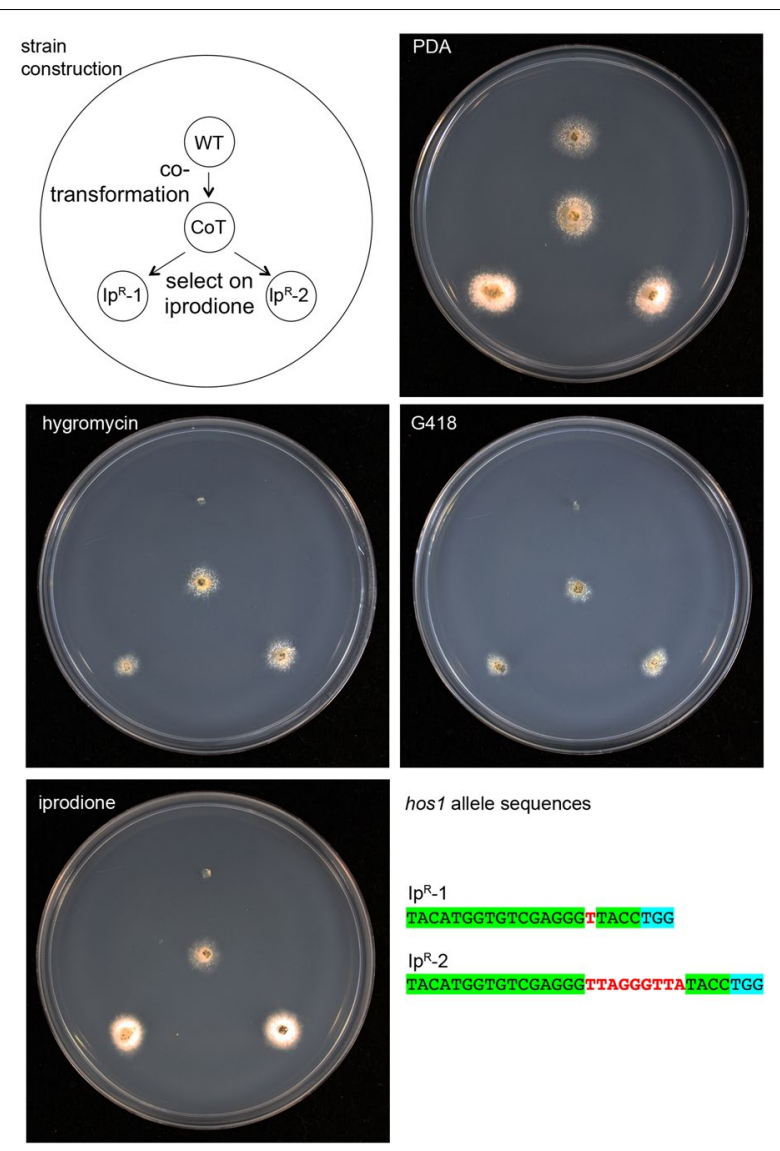

Fig. 5 Co-transformation of Cas9 and the CRISPR guide RNA constructs into L. maculans by Agrobacterium-mediated transformation. Wild type strain D13 was co-transformed with T-DNAs from both constructs, and selected on media containing both hygromycin and G418. One transformant (D13-CoT) was cultured on medium containing iprodione. Two independent resistant strains were obtained, their DNA isolated, and the hos 1 mutations determined by amplification and sequencing. The region incorporated into the guide RNA is highlighted in green, and adjacent PAM site in blue highlight. The two iprodione resistant strains have additional nucleotides (red font) within the hos 1 gene

or a guide RNA into L. maculans does not impact its pathogenicity.

\section{Improvements to mutation by CRISPR/Cas9}

One disadvantage of the method to induce mutations by the CRISPR/Cas9 system developed here was the need to perform two rounds of transformation, and hence cotransformation was therefore tested. The wild type strain D13 was co-transformed with both the hos1 RNA guide and Cas 9 constructs, with simultaneous co-selection on media containing G418 and hygromycin. One doubledrug resistant transformant (strain D13-CoT) was then cultured on medium containing iprodione, and two iprodione resistant isolates (D13- $\mathrm{Ip}^{\mathrm{R}} 1$ and $\left.\mathrm{D} 13-\mathrm{Ip}^{\mathrm{R}} 2\right)$ characterized by sequencing the hos 1 region (Fig. 5). Both strains have mutations caused by additional base pairs that can be attributed to the CRISPR-Cas9 system. While iprodione is generally considered non-mutagenic, the proportion of iprodione resistant spores were compared between the wild type D13 and the D13-CoT strains by culturing these in the absence of iprodione and then plating onto media with or without the fungicide. While the proportion of spores resistant to iprodione was less than 1 in 10,000 for the wild type, $54 \%$ of spores were resistant from the strain carrying the Cas9 endonuclease and hos1-guide construct.

To eliminate the requirement to order synthesized DNA fragments, which have to be cloned due to the complexity in secondary structure (Thermo Fisher Scientific), two plasmids were created that have the regions for the HDV ribozyme and Cas9-binding RNA. This new plasmid system was then used to target the first $A v r$ gene identified in L. maculans, AvrLm1. The hammerhead ribozyme and a region to target the AvrLm1 gene was synthesized as an 101 nucleotide oligonucleotide, amplified by PCR and cloned into the XhoI site of plasmid pMAI75. Cas9 was transformed into wild type strain v23.1.3, and then the guide RNA construct to mutate AvrLm1 was transformed into this strain. Genomic DNA isolated from the resulting transformants was used as the templates to amplify a fragment of AvrLm1, and amplicons then cut with NlaIII restriction enzyme. Two strains without the NlaIII site were obtained and AvrLm1 was amplified and sequenced from them. The mutant alleles had a single additional base pair or a 27 bp deletion (Additional file 5: Fig. S3). Thus, CRISPR-Cas9 can be used to isolate strains with mutations in genes, without a strong selection system as used for hos 1 .

\section{Discussion}

Resistance to fungicides is a major problem in many areas of disease management, especially in agriculture with the high levels of antifungals applied to ensure maximum yield returns. For example, currently in Australia canola growers may apply triazole fungicides three times during a season, including as a seed dressing, in combination with fertilizer and as a foliar spray [1]. Stubble is retained in the field after harvest, and the subsequent crop in the same field may receive fungicide treatments, thereby inadvertently causing additional exposure to the L. maculans populations while growing as a saprophyte in the canola stubble.

Resistance to iprodione and other dicarboximide fungicides and the underlying mechanisms have been well characterized in other plant pathogenic fungi, such as Botrytis cinerea [30-32]. The impact of mutation of hos1 
in plant pathogens varies, in some cases impacting pathogenicity and in others having no effect [16]. Hallmarks of impairing the HOG pathway, i.e. increased resistance to fludioxonil and sensitivity to salt, occur upon mutation of the hos1 gene in L. maculans, but the important ability to cause disease on plants is not. These results indicate that while iprodione is initially effective in vitro, resistance emerges easily, and these strains are still pathogenic on canola, potentially in part explaining the limited efficacy of iprodione in field conditions. Studies in other plant pathogenic fungi show differing results in terms of the contribution of the histidine kinase to pathogenicity. Similar to L. maculans, disruption of the gene does not impair pathogenicity in Alternaria alternata, Parastagonospora nodorum and Pyricularia oryzae [16, 33, 34]. In contrast, the homolog is required for pathogenicity in Botrytis cinerea, Fusarium oxysporum, Monilinia fructicola, Sclerotinia sclerotiorum and Ustilago maydis [35-39]. Deletion strains in Alternaria longipes form larger lesions on Nicotiana tabacum than the wild type [40]. There is ambiguity about the role of the gene in $A$. brassicicola with isolates with point mutations having wild type pathogenicity, while a deletion allele, albeit analyzed in a large scale study, being less pathogenic [41, 42]. The histidine kinase contributes to the virulence of the human pathogens Candida albicans and Cryptococcus neoformans $[43,44]$.

Leptosphaeria maculans continues to be a recurrent disease of oilseed Brassicas around the world because the factors that this fungus produces to cause disease are mostly unknown. One challenge with finding new ways to combat $L$. maculans is that identifying gene functions has been technically challenging. Gene disruption in $L$. maculans is inefficient, with only nine genes disrupted as reported in the literature [6-11]. Constructs require large amounts of DNA for targeting by homologous recombination and even then the proportion of gene deletion events versus ectopic integration of the constructs is low, e.g. an efficiency of just one knock out from $>450$ transformants screened [6]. Advances in improving the proportion of targeted gene replacements versus ectopic integrations have been made, including the use of a counter selection system against ectopic insertion events [9] or using the selectable marker split into two pieces [11]. However, isolating the large DNA fragments needed and/ or the cloning into suitable vectors imposes limitations to the efficiency of created targeted mutations. For this reason, alternative methods to disrupt genes are needed for L. maculans, and the method employing CRISPR-Cas9 was explored.

CRISPR/Cas is a combination of an endonuclease that is guided to a specific site in a genome using an RNA molecule, found in Bacteria and Archaea for recognition of parasitic DNA elements and their specific cleavage. Modified for use in other organisms, its ability to make specific double-stranded breaks in DNA that are then inaccurately repaired to induce small mutations, such as within genes, is on the cusp of revolutionizing methods for gene functional studies, including in fungal species that have until now been difficult to manipulate genetically.

Here we used iprodione resistance due to mutation of the hos1 gene as an easy screening tool to develop CRISPR/Cas9 for L. maculans. Iprodione resistant strains derived from strains expressing Cas9 and a guide RNA targeting hos1 all had mutations at the place within hos 1 where the endonuclease would cut the DNA. As proofof-function that the method could work on other genes, the first avirulence gene that was identified in this fungus, AvrLm1, was disrupted [45]. Targeting these effectors, all found to date to lie within distinctive large regions of AT-rich and highly repetitive DNA [5, 46], has not been possible using homologous recombination. Curiously, the avirulence profile of these strains did not change as predicted (data not shown), and will require additional experiments to understand what is emerging in L. maculans as complex multigene sets of interactions between fungal avirulence genes and plant resistance genes $[46,47]$.

In the first iteration of CRISPR/Cas9 for L. maculans, two rounds of transformation were used to separately introduce the guide RNA and Cas9 expression constructs into the fungus. After seeking a suitable promoter for regulation by RNA polymerase III in $L$. maculans without success, the dual ribozyme system to process the guide RNA when expressed from an RNA polymerase II promoter was used. This dual ribozyme approach was developed for plant transformation [48], and has recently also been employed in Aspergillus spp. [49], the basidiomycete human pathogen Cryptococcus neoformans [50] and the ascomycete plant pathogen Alternaria alternata [51]. The disadvantage of using ribozymes for processing the guide RNA is that they add size to the constructs. To alleviate this issue, we created a vector such that just one of the ribozymes and the RNA fragment to target Cas9 to the gene to be mutated are synthesized: the hammerhead ribozyme requires folding with part of the target RNA and hence there is a requirement for long $\sim 100$ nucleotide oligonucleotides. The current method, although involving two transformation steps or co-transformation of both constructs, is suitable for making targeted mutations in genes, and has been tested in multiple wild type isolates. We have mutated more than 24 other genes in L. maculans to date (unpublished data). Potential refinements to the method in the near future will likely make it even more effective as a mutational tool to discover gene functions in L. maculans. 


\section{Additional files}

Additional file 1: Table S1. Oligonucleotide primers used in this study.

Additional file 2. Sequence of the guide RNA constructs that were synthesized. Colors of the nucleotides infer different purposes. Blue, primer binding sites for amplification and cloning into plasmids; grey, ribozymes; red, 20 nucleotides specific to hos 1; purple, guide RNA; black, stop codon for trp3. Underlined nucleotides will base pair in the hammerhead ribozyme. Bold is the Xhol restriction enzyme site.

Additional file 3: Fig. S1. Constitutive expression of genes using the actin regulatory sequences. The L. maculans actin (act 1) promoter and $5^{\prime}$ UTR were cloned to allow expression of adjacent genes. In this case, GFP was fused to this region, and the construct transformed into L. maculans. Spores were germinated for 3 days in 10\% cleared V8 juice media. Bar $=50 \mu \mathrm{m}$.

Additional file 4: Fig. S2. Expression of the CRISPR components or mutation of hos 1 does not impair pathogenicity on plants. Cotyledons of B. napus $\mathrm{cv}$. Westar were inoculated with four strains, and lesions measured 14 days later. The wild type isolate D5 was sequentially transformed with the hos 1 guide RNA construct (to create strain DV1) and the Cas9 construct (DV2), and then plated on iprodione to isolate a resistant strain (DV3).

Additional file 5: Fig. S3. Targeted mutation of the AvrLm1 gene in $L$. maculans by CRISPR-Cas9. Alignment of the coding region of AvrLm 1 from wild type and two mutant alleles. On the wild type sequence the PAM is in blue highlight, region incorporated in the guide RNA in green, and the Nlalll restriction enzyme site used for screening is underlined. The differences in sequence in the two mutants are in red, as an extra A nucleotide or a deletion of 27 nucleotides.

\section{Authors' contributions}

$\mathrm{Al}, \mathrm{DRV}$, and FJL-R conceived and designed the project. Al, ASU, DRV, SC, APVdW, and FJL-R designed and performed the experiments, and analyzed the results. Al wrote the manuscript. All authors read and approved the final manuscript.

\section{Author details}

${ }^{1}$ School of BioSciences, University of Melbourne, Building 122, Parkville, VIC 3010, Australia. ${ }^{2}$ Department of Environment and Agriculture, Centre for Crop and Disease Management, Curtin University, Bentley, WA 6102, Australia.

\section{Acknowledgements}

We thank Edwin Lampugnani for providing the plasmid containing the Cas9 open reading frame.

\section{Competing interests}

The authors declare that they have no competing interests.

\section{Availability of data and materials}

All data generated or analyzed during this work are included in this article and its additional files.

\section{Consent for publication}

Not applicable.

\section{Ethics approval and consent to participate}

Not applicable.

\section{Funding}

The research was supported by the Australian Grains Research and Development Corporation (Projects CUR00023 and UM00050, and Scholarship GRS1 1006) and the Australian Research Council (Grant FT130100146).

\section{Publisher's Note}

Springer Nature remains neutral with regard to jurisdictional claims in published maps and institutional affiliations.
Received: 26 October 2017 Accepted: 12 December 2017

Published online: 16 December 2017

\section{References}

1. Van de Wouw AP, Marcroft SJ, Howlett BJ. Blackleg disease of canola in Australia. Crop Pasture Sci. 2016;67:273-83.

2. Mendes-Pereira E, Balesdent M-H, Brun H, Rouxel T. Molecular phylogeny of the Leptosphaeria maculans-L. biglobosa species complex. Mycol Res. 2003;107:1287-304

3. Voigt K, Cozijnsen AJ, Kroymann J, Pöggeler S, Howlett BJ. Phylogenetic relationships between members of the crucifer pathogenic Leptosphaeria maculans species complex as shown by mating type (MAT1-2), actin, and $\beta$-tubulin sequences. Mol Phylogenet Evol. 2005;37:541-57.

4. de Gruyter J, Woudenberg JHC, Aveskamp MM, Verkley GJM, Groenewald $\mathrm{JZ}$, Crous PW. Redisposition of Phoma-like anamorphs in Pleosporales. Stud Mycol. 2013;75:1-36.

5. Rouxel T, Grandaubert J, Hane JK, Hoede C, van de Wouw AP, Couloux A, Dominguez V, Anthouard V, Bally P, Bourras S, et al. Effector diversification within compartments of the Leptosphaeria maculans genome affected by repeat-induced point mutations. Nat Commun. 2011;2:202

6. Idnurm A, Taylor JL, Pedras MSC, Howlett BJ. Small scale functional genomics of the blackleg fungus, Leptosphaeria maculans: analysis of a $38 \mathrm{~kb}$ region. Australas Plant Pathol. 2003;32:511-9.

7. Idnurm A, Warnecke D, Heinz E, Howlett BJ. Characterisation of neutral trehalase and UDP-glucose: sterol glucosyltransferase genes from the plant pathogenic fungus Leptosphaeria maculans. Physiol Mol Plant Pathol. 2003;62:305-13.

8. Wilson LM, Idnurm A, Howlett BJ. Characterization of a gene (sp 1) encoding a secreted protein from Leptosphaeria maculans, the blackleg pathogen of Brassica napus. Mol Plant Pathol. 2002;3:487-93.

9. Gardiner DM, Howlett BJ. Negative selection using thymidine kinase increases the efficiency of recovery of transformants with targeted genes in the filamentous fungus Leptosphaeria maculans. Curr Genet. 2004;45:249-55.

10. Gardiner DM, Cozijnsen AJ, Wilson LM, Pedras MSC, Howlett BJ. The sirodesmin biosynthetic gene cluster of the plant pathogenic fungus Leptosphaeria maculans. Mol Microbiol. 2004;53:1307-18.

11. Feng J, Zhang H, Strelkov SE, Hwang S-F. The LmSNF1 gene is required for pathogenicity in the canola blackleg pathogen Leptosphaeria maculans. PLOS ONE. 2014;9:e92503.

12. Bahn Y-S. Master and commander in fungal pathogens: the twocomponent system and the HOG signaling pathway. Eukaryot Cell. 2008;7:2017-36.

13. Maeda T, Takekawa M, Saito H. Activation of yeast PBS2 MAPKK by MAPKKKs or by binding of an SH3-containing osmosensor. Science. 1995;269:554-8.

14. Posas F, Wurgler-Murphy SM, Maeda T, Witten EA, Thai TC, Saito H. Yeast HOG1 MAP kinase cascade is regulated by a multistep phosphorelay mechanism in the SLN1-YPD1-SSK1 "two-component" osmosensor. Cell. 1996;86:865-75.

15. Brewster JL, de Valoir T, Dwyer ND, Winter E, Gustin MC. An osmosensing signal transduction pathway in yeast. Science. 1993;259:1760-3.

16. John E, Lopez-Ruiz F, Rybak K, Mousley CJ, Oliver RP, Tan K-C. Dissecting the role of histidine kinase and HOG1 mitogen-activated protein kinase signalling in stress tolerance and pathogenicity of Parastagonospora nodorum on wheat. Microbiology. 2016;162:1023-36.

17. Van de Wouw AP, Elliott VL, Chang S, López-Ruiz FJ, Marcroft SJ, Idnurm A. Identification of isolates of the plant pathogen Leptosphaeria maculans with resistance to the triazole fungicide fluquinconazole using a novel in planta assay. PLoS ONE. 2017;12:e0188106.

18. Pitkin JW, Panaccione DG, Walton JD. A putative cyclic peptide efflux pump encoded by the TOXA gene of the plant-pathogenic fungus Cochliobolus carbonum. Microbiology. 1996;142:1557-65.

19. Van de Wouw AP, Thomas VL, Cozijnsen AJ, Marcroft SJ, Salisbury PA, Howlett BJ. Identification of Leptosphaeria biglobosa'canadensis' on Brassica juncea stubble from northern New South Wales, Australia. Aust Plant Dis Notes. 2008;3:124-8. 
20. Walton FJ, Idnurm A, Heitman J. Novel gene functions required for melanization of the human pathogen Cryptococcus neoformans. Mol Microbiol. 2005;57:1381-96.

21. Elliott CE, Howlett BJ. Overexpression of a 3-ketoacyl-CoA thiolase in Leptosphaeria maculans causes reduced pathogenicity on Brassica napus. Mol Plant Microbe Interact. 2006;19:588-96.

22. Covert SF, Kapoor P, Lee M-H, Briley A, Nairn CJ. Agrobacterium tumefaciens-mediated transformation of Fusarium circinatum. Mycol Res. 2001;105:259-64.

23. Xing $\mathrm{H}-\mathrm{L}$, Dong L, Wang Z-P, Zhang H-Y, Han C-Y, Liu B, Wang X-C, Chen Q-J. A CRISPR/Cas9 toolkit for multiplex genome editing in plants. BMC Plant Biol. 2014;14:327.

24. Bundock P, den Dulk-Ras A, Beijersbergen A, Hooykaas PJJ. Trans-kingdom T-DNA transfer from Agrobacterium tumefaciens to Saccharomyces cerevisiae. EMBO J. 1995;14:3206-14.

25. Eckert MR, Rossall S, Selley A, Fitt BDL. Effects of fungicides on in vitro spore germination and mycelial growth of the phytopathogens Leptosphaeria maculans and L. biglobosa (phoma stem canker of oilseed rape). Pest Manag Sci. 2010;66:396-405.

26. Elliott VL, Marcroft SJ, Howlett BJ, Van de Wouw AP. Gene-for-gene resistance is expressed in cotyledons, leaves and pods, but not during late stages of stem colonisation in the Leptosphaeria maculans-Brassica napus pathosystem. Plant Breeding. 2016;135:200-7.

27. Grigoriev IV, Nikitin R, Haridas S, Kuo A, Ohm R, Otillar R, Riley R, Salamov A, Zhao X, Korzeniewski F, et al. MycoCosm portal: gearing up for 1000 fungal genomes. Nucleic Acids Res. 2014;42:D699-704.

28. Lowe RGT, Cassin A, Grandaubert J, Clark BL, Van de Wouw AP, Rouxel T, Howlett BJ. Genomes and transcriptomes of partners in plant-fungalinteractions between canola (Brassica napus) and two Leptosphaeria species. PLOS ONE. 2014;9:e103098.

29. Plissonneau C, Daverdin G, Ollivier B, Blaise F, Degrave A, Fudal I, Rouxel T, Balesdent M-H. A game of hide and seek between avirulence genes AvrLm4-7 and AvrLm3 in Leptosphaeria maculans. New Phytol. 2016;209:1613-24.

30. Grabke A, Fernández-Ortuño D, Amiri A, Li X, Peres NA, Smith P, Schnabel $\mathrm{G}$. Characterization of iprodione resistance in Botrytis cinerea from strawberry and blackberry. Phytopathology. 2014;104:396-402.

31. Liu W, Leroux P, Fillinger S. The HOG1-like MAP kinase Sak1 of Botrytis cinerea is negatively regulated by the upstream histidine kinase Bos 1 and is not involved in dicarboximide- and phenylpyrrole-resistance. Fungal Genet Biol. 2008;45:1062-74.

32. Cui W, Beever RE, Parkes SL, Weeds PL, Templeton MD. An osmosensing histidine kinase mediates dicarboximide fungicide resistance in Botryotinia fuckeliana (Botrytis cinerea). Fungal Genet Biol. 2002;36:187-98.

33. Lin C-H, Chung K-R. Specialized and shared functions of the histidine kinase- and HOG1 MAP kinase-mediated signaling pathways in Alternaria alternata, a filamentous fungal pathogen of citrus. Fungal Genet Biol. 2010;47:818-27.

34. Motoyama T, Kadokura K, Ohira T, Ichiishi A, Fujimura M, Yamaguchi I, Kudo T. A two-component histidine kinase of the rice blast fungus is involved in osmotic stress response and fungicide action. Fungal Genet Biol. 2005;42:200-12.

35. Viaud M, Fillinger S, Liu W, Polepalli JS, Le Pêcheur P, Kunduru AR, Leroux $P$, Legendre L. A class III histidine kinase acts as a novel virulence factor in Botrytis cinerea. Mol Plant Microbe Interact. 2006;19:1042-50.

36. Rispail N, Di Pietro A. The two-component histidine kinase Fhk1 controls stress adaptation and virulence of Fusarium oxysporum. Mol Plant Pathol. 2010;11:395-407.

37. Ma Z, Luo Y, Michailides T. Molecular characterization of the two-component histidine kinase gene from Monilinia fructicola. Pest Manag Sci. 2006;62:991-8.

38. Duan Y, Ge C, Liu S, Wang J, Zhou M. A two-component histidine kinase Shk1 controls stress response, sclerotial formation and fungicide resistance in Sclerotinia sclerotiorum. Mol Plant Pathol. 2013;14:708-18.

39. Yun YH, Oh MH, Kim JY, Kim SH. UmTco 1, a hybrid histidine kinase gene, is essential for the sexual development and virulence of Ustilago maydis. J Microbiol Biotechnol. 2017;27:1010-22.

40. Luo YY, Yang JK, Zhu ML, Liu CJ, Li HY, Lu ZB, Pan WZ, Zhang ZH, Bi W, Zhang KQ. The group III two-component histidine kinase AlHK1 is involved in fungicides resistance, osmosensitivity, spore production and impacts negatively pathogenicity in Alternaria longipes. Curr Microbiol. 2012;64:449-56.

41. Cho Y, Kim KH, La Rota M, Scott D, Santopietro G, Callihan M, Mitchell TK, Lawrence CB. Identification of novel virulence factors associated with signal transduction pathways in Alternaria brassicicola. Mol Microbiol. 2009; 72:1316-33.

42. Iacomi-Vasilescu B, Bataille-Simoneau N, Campion C, Dongo A, Laurent E, Serandat I, Hamon B, Simoneau P. Effect of null mutations in the AbNIK1 gene on saprophytic and parasitic fitness of Alternaria brassicicola isolates highly resistant to dicarboximide fungicides. Plant Pathol. 2008;57:937-47.

43. Bahn Y-S, Kojima K, Cox GM, Heitman J. A unique fungal two-component system regulates stress responses, drug sensitivity, sexual development, and virulence of Cryptococcus neoformans. Mol Biol Cell. 2006;17:3122-35.

44. Yamada-Okabe T, Mio T, Ono N, Kashima Y, Matsui M, Arisawa M, YamadaOkabe H. Roles of three histidine kinase genes in hyphal development and virulence of the pathogenic fungus Candida albicans. J Bacteriol. 1999;181:7243-7.

45. Gout L, Fudal I, Kuhn M-L, Blaise F, Eckert M, Cattolico L, Balesdent $\mathrm{M}-\mathrm{H}$, Rouxel T. Lost in the middle of nowhere: the AvrLm1 avirulence gene of the Dothideomycete Leptosphaeria maculans. Mol Microbiol. 2006;60:67-80.

46. Rouxel T, Balesdent M-H. Life, death and rebirth of avirulence effectors in a fungal pathogen of Brassica crops, Leptosphaeria maculans. New Phytol. 2017;214:526-32.

47. Petit-Houdenot Y, Fudal I. Complex interactions between fungal avirulence genes and their corresponding plant resistance genes and consequences for disease resistance management. Front Plant Sci. 1072;2017:8.

48. Gao Y, Zhao Y. Self-processing of ribozyme-flanked RNAs into guide RNAs in vitro and in vivo for CRISPR-mediated genome editing. J Integr Plant Biol. 2014;56:343-9.

49. Nødvig CS, Nielsen JB, Kogle ME, Mortensen UH. A CRISPR-Cas9 system for genetic engineering of filamentous fungi. PLOS ONE. 2015;10:e0133085.

50. Arras SDM, Chua SMH, Wizrah MSI, Faint JA, Yap AS, Fraser JA. Targeted genome editing via CRISPR in the pathogen Cryptococcus neoformans. PLOS ONE. 2016;11:e0164322.

51. Wenderoth M, Pinecker C, Voß B, Fischer R. Establishment of CRISPR/Cas9 in Alternaria alternata. Fungal Genet Biol. 2017;101:55-60.

52. Van de Wouw AP, Marcroft SJ, Ware A, Lindbeck K, Khangura R, Howlett $\mathrm{BJ}$. Breakdown of resistance to the fungal disease, blackleg, is averted in commercial canola (Brassica napus) crops in Australia. Field Crops Res. 2014;166:144-51.

\section{Submit your next manuscript to BioMed Central and we will help you at every step:}

- We accept pre-submission inquiries

- Our selector tool helps you to find the most relevant journal

- We provide round the clock customer support

- Convenient online submission

- Thorough peer review

- Inclusion in PubMed and all major indexing services

- Maximum visibility for your research

Submit your manuscript at www.biomedcentral.com/submit 